\title{
Complejo de esclerosis tuberosa de diagnóstico tardío
}

\section{Tuberous Sclerosis Complex of Late Onset}

\author{
Cherina Herazo Bustos ${ }^{1}$ Catalina Wilches Vanegas ${ }^{2}$ \\ ${ }^{1}$ Fundación Universitaria Sanitas - Clínica Universitaria Colombia, \\ Bogotá, Colombia \\ ${ }^{2}$ Clínica Reina Sofía, Bogotá, Colombia
}

Rev Argent Radiol 2018;82:131-133.

Estimados Editores,

El complejo esclerosis tuberosa, es una enfermedad autosómica dominante de penetrancia incompleta que se estima afecta de $1 / 6000$ a $1 / 12000$ personas, siendo $2 / 3$ de los casos esporádicos, con mortalidad antes de los 35 años de hasta el $40 \%{ }^{1}$ Algunos estudios reportan una edad promedio de presentación de 7,5 años. ${ }^{2}$ Está incluida en el grupo de las facomatosis o síndromes neurocutáneos y se caracteriza por hamartomas principalmente en el cerebro, retina, riñones, piel y corazón. ${ }^{3}$

La tríada clásica e infrecuente de Vogt incluye retraso mental, epilepsia y adenomas sebáceos, ${ }^{1}$ sin embargo, hasta el $50 \%$ de los pacientes que cumplen los criterios tienen intelecto normal y el 15\% no presenta convulsiones.

Presentamos el caso de un hombre de 37 años, sin antecedentes de importancia, que acudió al servicio de consulta externa de ortopedia por presentar masas ungueales en manos y pies, donde además se evidenciaron manchas color café con leche en piel. Se realizó una resonancia magnética de los dedos de las manos (-Fig. 1) en la cual se notaban lesiones periungueales que fueron resecadas.

Luego del nacimiento del hijo del paciente, que fue diagnosticado con esclerosis tuberosa, se le realizó al paciente una tomografía contrastada de abdomen y resonancia magnética cerebral en busca de lesiones compatibles con esclerosis tuberosa (-Fig. 2), evidenciando túberes corticales en esta última.

Debido a la presencia de displasia cortical, fibromas ungueales y lesiones hipomelanóticas en confeti, y luego de pruebas genéticas pertinentes, se realizó el diagnóstico de esclerosis tuberosa de penetrancia incompleta con presentación en la edad adulta.

Antiguamente el complejo esclerosis tuberosa (CET) era conocido como esclerosis tuberosa o enfermedad de Pringle Bourneville; sin embargo, por la variabilidad de fenotipos y evidencia de más de un gen causante de la enfermedad, se
Address for correspondence Cherina Herazo Bustos, Fundación Universitaria Sanitas, Calle 23 \# 66-46, Departamento de Radiología, Bogotá, Colombia (e-mail: cherihb4@hotmail.com). prefiere ahora el término de CET. ${ }^{4}$ El rango de diagnóstico varía de los 0-67 años. ${ }^{3}$ Un estudio realizado comparó los hallazgos en mujeres con presentación en la infancia y en edad adulta, mostrando que en las últimas hay menor número de criterios mayores, una presentación tardía de las manifestaciones cutáneas, menor incidencia de convulsiones y mayor probabilidad de presentar linfangioleiomiomatosis $\mathrm{y}$ angiomiolipomas al momento del diagnóstico. ${ }^{3}$

Se pueden visualizar diversas lesiones en imágenes diagnósticas, entre ellas, displasias corticales: son anomalías congénitas causadas por la falla de migración neural. En esta categoría se incluyen los túberes corticales y las líneas radiales de migración de sustancia blanca. Cerca del 90\% de los túberes corticales se encuentran en los lóbulos frontales y calcifican después de los dos años de vida; en secuencias ponderadas en T2 y FLAIR son áreas hiperintensas en la región cortical y subcortical con realce posterior a la administración de medio de contraste en el $3-4 \%$ de los $\operatorname{casos}^{5}$; dependiendo de su localización, pueden causar anomalías cognitivas, déficits de los pares craneales o anomalías sensoriales. ${ }^{5}$ Se considera que las líneas de migración radiales de sustancia blanca representan glía heterotópica y neuronas a través de un camino de migración cortical esperado. Se encuentran localizadas en la sustancia blanca subcortical y pocas veces se relacionan con los túberes. ${ }^{6}$

Otra lesión visualizada son los nódulos subependimarios: representan hamartomas en el tejido subependimario; por el alto porcentaje de nódulos calcificados (88\%) son fácilmente reconocibles en la tomografía, sin embargo esas calcificaciones están ausentes en la edad pediátrica. En la resonancia magnética son hiperintensos en secuencias ponderadas en $\mathrm{T} 1 \mathrm{e}$ iso/ hiperintensos en secuencias ponderadas en $\mathrm{T} 2$, con intensidad de señal disminuida en secuencias ponderadas en $\mathrm{T} 2$ respecto a los túberes corticales por el menor contenido de agua. ${ }^{1}$

También podemos mencionar el astrocitoma subependimario de células gigantes: se considera que se received

May 19, 2017

accepted

September 2, 2017

published online

March 23, 2018
DOI https://doi.org/

10.1055/s-0038-1639380.

ISSN 1852-9992.
Copyright @ $\odot 2019$, Sociedad Argentina de Radiología. Publicado por Thieme Revinter Publicações Ltda., Rio de Janeiro, Brazil. Todos los derechos reservados.
License terms

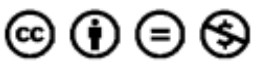




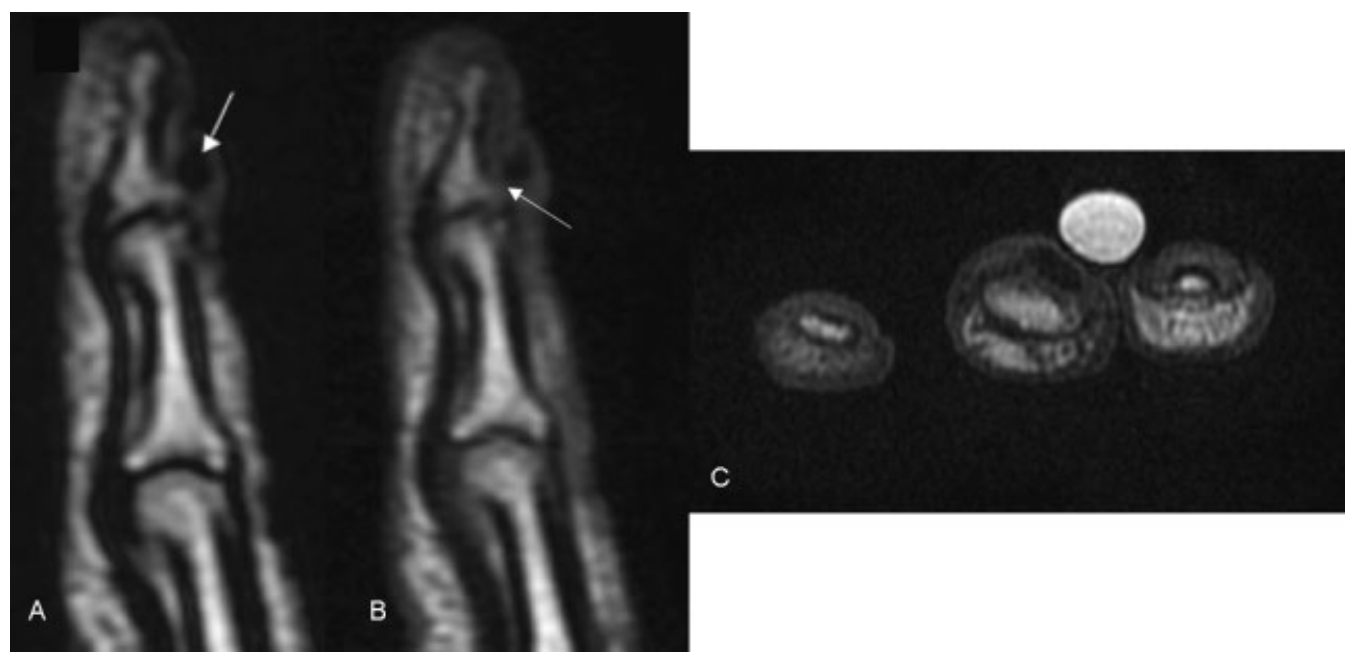

Fig. 1 Secuencias sagitales ponderadas en T2 y T1 de resonancia magnética (RM) del tercer dedo (A y B). Imagen axial densidad de protones (C). Las flechas señalan una lesión adyacente al tendón extensor en el aspecto proximal de la falange distal, la cual mide $7 \mathrm{~mm}$ de longitud, es hipointensa en secuencias ponderadas en $\mathrm{T} 2$ y densidad de protones e isointensa en secuencias ponderadas en $\mathrm{T} 1$, en relación a fibromas ungueales.

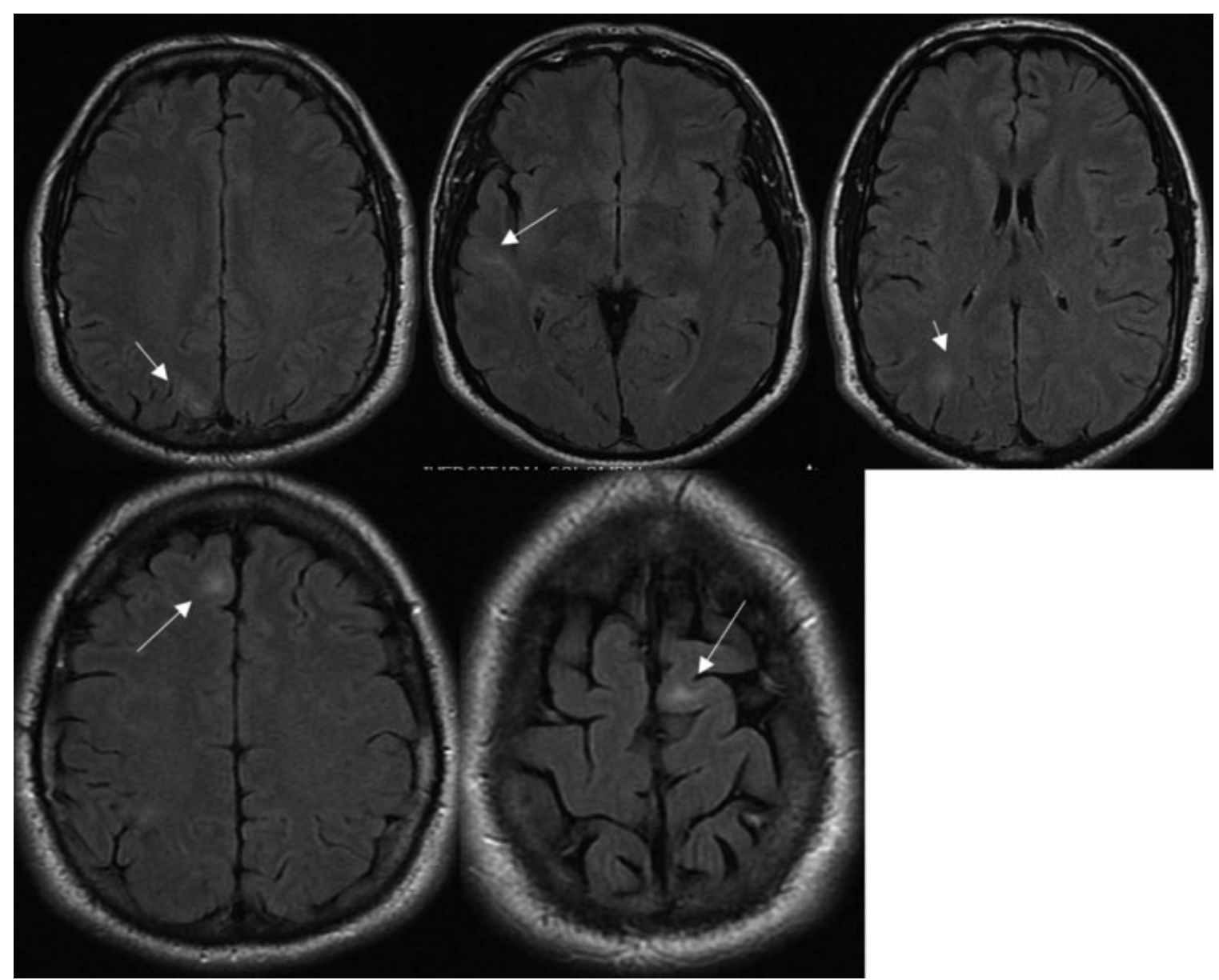

Fig. 2 RM en imágenes FLAIR axiales. Las flechas blancas muestran lesiones hiperintensas en la sustancia blanca subcortical en localización parietal, frontal y occipital derechas y temporal izquierda sin efecto de masa ni edema asociado, compatibles con túberes corticales.

originan por el crecimiento de los nódulos subependimarios, ${ }^{7}$ y son células gigantes y astrocitos proliferativos que se encuentran con más frecuencia en el foramen de Monro, por tanto, debutan como hidrocefalia. ${ }^{1}$ Suelen ser de crecimiento lento, con escaso edema cerebral y mínima invasión.
La linfangioleiomiomatosis es una enfermedad rara e idiopática en la que existe proliferación difusa de células musculares y cambios quísticos del parénquima. Afecta principalmente a los pulmones, en tomografía computada se observan quistes de paredes delgadas de distribución simétrica y difusa, los cuales se comunican con la vía aérea. ${ }^{8}$ 
Por último, las angiomiolipomas son tumores benignos formados de tejido vascular, músculo liso y tejido adiposo, cuya localización más frecuente son los riñones. En la tomografía, se identifican como tumores con atenuación menor a $-20 \mathrm{UH}^{1}{ }^{1}$ en la ecografía son homogéneos, hiperecoicos o isoecoicos al músculo liso. ${ }^{9} \mathrm{Al}$ ser evaluados con resonancia magnética, presentan artificio de tinta china en la periferia en las secuencias fuera de fase y pérdida de la intensidad de señal en las secuencias con saturación grasa. ${ }^{9}$

El CET es una patología en la que el radiólogo juega un papel fundamental al sugerir su diagnóstico en caso de evidenciar displasias corticales, nódulos subependimarios, astrocitoma subependimario, linfagioleiomiomatosis y angiomiolipomas en pacientes que no tengan este antecedente o sean asintomáticos. Por tanto, es importante recordar los múltiples órganos y sistemas que se pueden comprometer para poder realizar intervenciones tempranas en calidad de vida personal y en la consejería genética a nivel familiar.

Confidencialidad de los datos

Los autores declaran que han seguido los protocolos de su centro de trabajo sobre la publicación de datos de pacientes y que todos los pacientes incluidos en el estudio han recibido información suficiente y han dado su consentimiento informado por escrito para participar en dicho estudio.

\section{Conflicto de intereses}

Los autores declaran no tener ningún conflicto de intereses.

\section{Bibliografía}

1 Umeoka S, Koyama T, Miki Y, Akai M, Tsutsui K, Togashi K. Pictorial review of tuberous sclerosis in various organs. Radiographics 2008;28(07):e32

2 Staley BA, Vail EA, Thiele EA. Tuberous sclerosis complex: diagnostic challenges, presenting symptoms, and commonly missed signs. Pediatrics 2011;127(01):e117-e125

3 Seibert D, Hong C-H, Takeuchi F, et al. Recognition of tuberous sclerosis in adult women: delayed presentation with lifethreatening consequences. Ann Intern Med 2011;154(12): 806-813, W-294

4 Northrup H, Krueger DA; International Tuberous Sclerosis Complex Consensus Group. Tuberous sclerosis complex diagnostic criteria update: recommendations of the 2012 Iinternational Tuberous Sclerosis Complex Consensus Conference. Pediatr Neurol 2013;49(04):243-254

5 Kalantari BN, Salamon N. Neuroimaging of tuberous sclerosis: spectrum of pathologic findings and frontiers in imaging. AJR Am J Roentgenol 2008;190(05):W304-9

6 Griffiths PD, Bolton P, Verity C. White matter abnormalities in tuberous sclerosis complex. Acta Radiol 1998;39(05): 482-486

7 Morimoto K, Mogami H. Sequential CT study of subependymal giant-cell astrocytoma associated with tuberous sclerosis. Case report. J Neurosurg 1986;65(06):874-877

8 Pallisa E, Sanz P, Roman A, Majó J, Andreu J, Cáceres J. Lymphangioleiomyomatosis: pulmonary and abdominal findings with pathologic correlation. Radiographics 2002;22(Spec No): S185-S198

9 Jinzaki M, Silverman SG, Akita H, Nagashima Y, Mikami S, Oya M. Renal angiomyolipoma: a radiological classification and update on recent developments in diagnosis and management. Abdom Imaging 2014;39(03):588-604 